\title{
Psychological Stress Experienced by Final Year Nursing Students: Role of the clinical environment
}

\author{
Norhayati Nasir, Zamzaliza Abdul Mulud \\ Centre for Nursing Study, Faculty of Health Sciences, UiTM Selangor, Puncak Alam Campus, \\ 42300 Bandar Puncak Alam, Selangor, Malaysia \\ norhayatishamsuri@yahoo.com, zamzaliza@uitm.edu.my \\ Tel: $012-5072556$
}

\begin{abstract}
Previous studies have shown that nursing students do experience stress. This study adopted the Transactional Stress and Coping Model (Lazarus and Folkman, 1984) to examine the clinical environment factors associated with stress experienced by nursing students. The cross-sectional study design was used, and data were collected over a two-month period in 2019. A self-administered questionnaire was used to collect data. 420 samples were recruited using the simple random sampling technique. Based on the one-way ANOVA test, there was a significant mean difference between primary appraisal scores and secondary appraisal scores. The resilience level was significantly associated with the level of stress.
\end{abstract}

Keywords: nursing students, stress, resilience

eISSN: 2398-4287@ 2020. The Authors. Published for AMER ABRA CE-Bs by e-International Publishing House, Ltd., UK. This is an open-access article under the CC BYNC-ND license (http://creativecommons.org/licenses/by-nc-nd/4.0/). Peer-review under responsibility of AMER (Association of Malaysian Environment-Behaviour Researchers), ABRA (Association of Behavioural Researchers on Asians) and cE-Bs (Centre for Environment-Behaviour Studies), Faculty of Architecture, Planning \& Surveying, Universiti Teknologi MARA, Malaysia.

DOI: https://doi.org/10.21834/ebpj.v5i14.2216

\subsection{Introduction}

The basic Diploma in Nursing course covers the theory and clinical competency training parts formulated to empower nursing students with professional responsibility. Clinical placement and training are an essential part of the diploma curriculum that strengthens the necessary skills and professional achievement among nursing students. Clinical activities allow nursing students to learn, practice and develop critical knowledge, skills, and values in the nursing profession. Numerous studies support the existence of serious adverse consequences associated with the variable of stress. Nursing students experience either low, moderate or high levels of stress because they frequently encounter various challenges that negatively affect their academic performance and general health. However, familiar sources of stress among nursing students have not been well identified (Alghamdi, 2019). The purpose of this study is to determine the familiar sources of stress, focusing primarily on final year nursing students. The adverse stress-related outcomes have the potential to emerge as feelings of helplessness, depression, anger, anxiety, and cognitive recall, lack of concentration, which leads to issues such as immune deficiency disorders, depression and suicide. These experiences subsequently have the potential to decrease learning capabilities, academic performance and retention (Lee, 2007; Goff, 2011; Yamashita, 2012; Townsend, 2015).

\subsection{Literature Review}

Discussion based on a literature review of 20 articles were analysed by this study to determine the factors related to stress among nursing students undergoing clinical placement. The causes of stress among these nursing students were due to academic workloads, such as preparing assignments and presenting case studies during clinical placement, worrying about low grades during routine 
assessments in the hospital ward, negative attitude shown by qualified nurses, doctors and support staff towards nursing students, patient care responsibilities, humiliation by medical students and physicians, unwillingness of qualified nurses to accept male nurses and finally, worrying about making mistakes during procedures that could endanger patients' lives (Pulido-Martos et al., 2012; Altiok \& Ustun, 2013; Boardman, 2016, Masilamani, 2019). Studies also show that nursing students suffer from a high degree of stress during clinical practise (Liu et al., 2015; Sun et al., 2016; Hamaideh et al., 2017). Moreover, nursing students also experience varying degrees of stress across clinical courses.

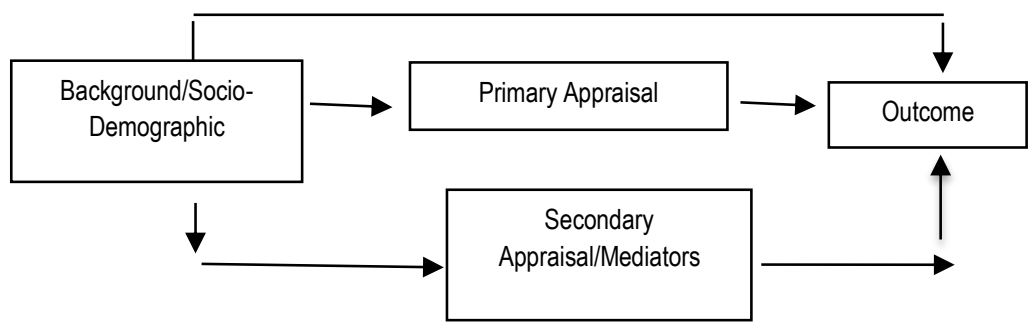

Fig. 2.1: The Transactional Model of Stress and Coping (Lazarus \& Folkman, 1984)

Rees et al. (2015), in a study done in Australia and Shaher (2017), in a study done in Jordan, had discussed severe levels of stress in nursing students using the Individual Psychological Resilience Model, similar to that used in this study. However, their studies did not discuss this adaption model thoroughly. In the model concerning stress, causes and results of stress reactions, Lazarus and Folkman (1984) suggested that there is a series of appraisals (causes or stimulants) that causes stress in individuals. The stimulus reduces the ability or resources; the second stimulus will reduce the ability or resources, whether it provides excellent benefits or otherwise and the third is how best to use a coping mechanism in this situation or stimuli to overcome stress. Lazarus and Folkman (1984) defined appraisal as a process whereby an individual assesses the environment to determine whether a stimulant can threaten the well-being of the individual involved. Lazarus and Folkman (1984) further detailed appraisals into two (2) parts, namely primary and secondary appraisals.

Conclusions based on a literature review of 20 articles were analysed by this study and found insufficient evidence from past studies Western countries (Hodges, 2008; Podsakoff, 2011; Lepine, 2012; Jones Giavana, 2014; Diane, 2016), Saudi Arabia (Hamaideh, 2017), Hong Kong (Wong, 2017), Turkey (Razieh Tadayon, 2011; Altiok, 2013; Yildrim, 2017) and Jourdan (Wejdan, 2014; Al-Zayyat, 2015). A review of previous studies found only two studies that were related to stress experienced by nursing students in Malaysia. Based on this review, it was noted that stress occurred among nursing students, but the theory or model used in the studies were not discussed in detail. Therefore, this study was deemed necessary based on the adapted Transactional Model of Stress and Coping to determine the level of stress among final year nursing students in Malaysia.

\subsection{Methodology}

\subsection{Conceptual Framework of the Study.}

The conceptual framework applied in this study is based on the Transactional Model of Stress and Coping by Lazarus and Folkman (1984). The Transactional Model of Stress and Coping is a framework for evaluating the process of coping when facing stressful situations. The purpose of this framework is to determine the relationship between demographic variables (age, gender, type of family, family income, ethnic group, and CGPA) and appraisals or factors that trigger stress (clinical placement), which are related to stressors among final year nursing students in Malaysia and outcomes (stress and coping).

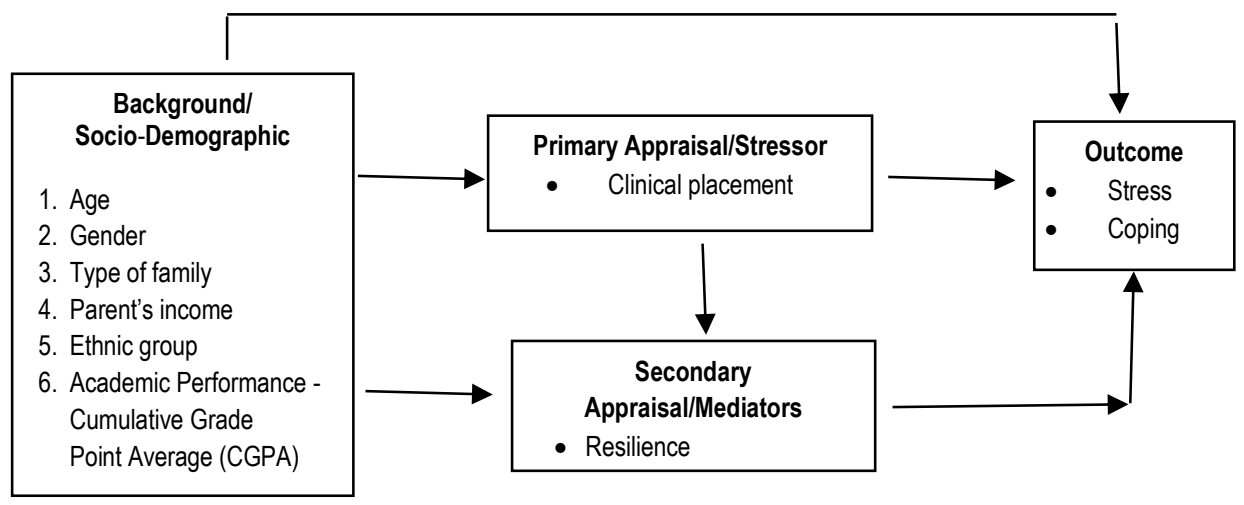

Fig. 3.1: Adapted from The Transactional Model of Stress and Coping (Lazarus \& Folkman, 1984). 


\subsection{Objectives of the study}

1. To identify the levels of stress among final year nursing students in Malaysia.

2. To determine the association between socio-demographic characteristics of final year nursing students with level of stress.

\subsection{Study design}

A quantitative cross-sectional design was used in this study. The purpose of this design method is to obtain results that are more detailed and in-depth, to be complementary, to answer questions and achieve the objective of the study, which covers the scope parallel to the environment and current trends of stress-related problems encountered by final year nursing students.

\subsection{Instruments for data collection}

This study had used closed-ended questions to gather data from the respondents. A set of questionnaires consisting of 4 sections was used to obtain data. Section 1 concerns demographic data related to stress, such as age, gender, type of family, parent's income, ethnic group and, academic achievement or the respondent's CGPA. Section 2 concerns the stress level among final year nursing students, which was gauged using the Perceived Stress Scale-PSS (Cohen et al., 1983). Section 3 concerns the structured items on resilience, which was measured using the Conor-Davidson Resilience Scale (CD-RISC) by Connor \& Davidson (2003). Section 4 concerns the Primary appraisal, which used the Stressors Nursing Students Scale (SNSI).

\begin{tabular}{|c|c|c|c|}
\hline Instrument. & No of Item & Scale. & Internal Consistency \\
\hline Demographic & 5 & - & - \\
\hline Stress & 10 & $\begin{array}{l}\text { The Perceived Stress Scale } \\
\text { (PSS). Cohen et al., } 1983 .\end{array}$ & Cronbach's alpha between .68 and .80 \\
\hline Primary Appraisal & 25 & $\begin{array}{l}\text { The Stressors Nursing Students } \\
\text { Scale (SNSI). Jones \& Johnston, }\end{array}$ & Cronbach's alpha .68 and .87 \\
\hline Resilience & 25 & $\begin{array}{l}\text { The Conor-Davidson Resilience } \\
\text { Scale (CD-RISC). Connor \& Davidson, } 2003 .\end{array}$ & Cronbach's alpha .93 \\
\hline
\end{tabular}

\subsection{Study Setting.}

The sample consisted of 420 final year nursing students representing nursing training institutes under the auspices of the Malaysian Ministry of Health and were selected using the simple random sampling method. The institutes involved in this study were chosen to represent a particular zone. The selected institutes were ILKKM Alor Setar (Kedah), ILKKM Pulau Pinang and ILKKM Sultan Azlan Shah (Perak) representing the North zone; ILKKM Sungai Buluh (Selangor), ILKKM Kuala Pilah (Negeri Sembilan) and ILKKM Melaka representing the West zone; ILKKM Johor Baharu (Johor), ILKKM Muar (Johor) and ILKKM Batu Pahat (Johor) representing the South zone and ILKKM Kubang Kerian (Kelantan), and ILKKM Kuantan (Pahang) representing the East zone.

\subsection{Population (N)}

The population included all final year nursing student's enrolled in the Diploma in Nursing course in the various ILKKMs. Currently, there are 3553 students enrolled in 16 ILKKMs in Malaysia and 2730 are final year nursing students (Nursing Board Malaysia, 2017-2018).

\subsection{Samples (n).}

This study used the Krejcie and Morgan Formula (1970), whereby the total number of samples comprised 420 final year nursing students. A two-stage sampling technique was used to select a total of 420 samples from selected ILKKMs in four (4) regions in Peninsular Malaysia, namely the North, South, East and West Malaysia. The first stage of sampling used the proportional stratified sampling method to select the respective ILKKMs for this study. In the second stage, simple random sampling was used to obtain samples from all four (4) regions. The sampling frame was the name list of all final year nursing students from the identified ILKKMs in phase one of the sampling. A number (1 to 1490) was assigned to each student's name, and 420 random numbers were generated using a computer software. The purpose of using this sampling technique was to reduce selection bias and the sample would accurately reflect the population.

\subsection{Limitations of the study.}

This study has its own strengths and constraints. Factors that could be avoided in response to the objectives of the study are as follows:

i. Limited samples did not represent nursing students from all over Malaysia (government, higher institution education and private sectors); hence, the findings of this study cannot be generalised to the whole Malaysian nursing student population.

ii. The study looked at the education aspect; thus, the results of this study will be used for learning purposes.

iii. Data were obtained through a questionnaire survey that was completed by the respondents. Accuracy of the data depend on the respondent's honesty when answering the questionnaire. Various factors can influence the respondents, which could result in inaccurate findings with one of the factors being the respondent's understanding of the continuing education concept. 
iv. Majority of participants were Malays, with minimal Chinese and Indian participants and did not including Sabah and Sarawak Bumiputera. Thus, it is recommended that future studies cover other states for a more representative sampling of all multiracial ethnic groups in Malaysia.

\subsection{Data Collection - Process.}

The process began by obtaining the approval from UiTM (ethical aspect requirement), application letter and approval from selected ILKKM directors, distributing research questionnaires to respondents and finally, data analysis.

\subsection{Pilot Study.}

The purpose of a pilot study is to validate and confirm the reliability of the questions in the questionnaire. This study had adhered to the criterion of "the sample setting formula for a pilot study is $10 \%$ of the final respondents" (Treece in 1985). The final year nursing students at ILKKM Sungai Petani, Kedah who were not involved in the actual study had taken part in the pilot study (42 respondents).

\subsection{Data Analysis.}

Data and information were obtained from responses provided by respondents through a questionnaire comprising closed-ended questions that was distributed by the coordinator in-charge of final year nursing students at selected ILKKMs. The raw data were analysed through descriptive and inferential analyses methods using SPSS version 22.

\subsection{Findings.}

This study has shown that final year nursing students do experience a moderate level of stress. Studies have also indicated that the main stress factor is clinical placements. Based on the one-way ANOVA, there is a significant mean difference between primary appraisal scores and secondary appraisal scores. Majority of the respondents were between $22-25$ years of age, females ( $n=417$, $99.3 \%)$, Malays $(n=399,95.0 \%)$, and followed by other ethnic backgrounds $(n=21,5.0 \%)$. The family circle consisted of the nuclear family $(n=382,91.0 \%)$ followed with the joint family $(n=38,9 \%)$. The total family household monthly income was less than RM 5000.00 $(n=350,83.3 \%)$ and the rest was more than RM $5000.00(n=70,16.7 \%)$, while the CGPA results were in the range of less than 2.50 $(n=19,4.5 \%), 2.51-2.99(n=13,3.1 \%), 3.00-3.49(n=151,36.0 \%)$ and finally, $3.50-3.99(n=237,56.4 \%)$.

Table 4.1. Mean Difference of Resilience and Stressor Score Factors Between Levels of Stress among Nursing Students Using the One-way ANOVA

\begin{tabular}{|c|c|c|c|}
\hline Appraisal Score vs Level of Stress & Mean diff $(95 \% \mathrm{Cl})$ & $\begin{array}{c}{ }^{*} p \\
\text { value }^{b}\end{array}$ & $\begin{array}{c}\text { F statistic }^{a} \\
\text { ( } p \text { value) }\end{array}$ \\
\hline \multicolumn{4}{|l|}{ Resilience Score } \\
\hline Low - Moderate & $8.23(2.84,13.62)$ & 0.001 & \multirow{3}{*}{$9.57(<0.001)$} \\
\hline Low - Severe & $15.66(6.13,25.19)$ & $<0.001$ & \\
\hline Severe - Moderate & $7.43(-0.71,15.56)$ & 0.087 & \\
\hline \multicolumn{4}{|l|}{ Stress Due to Clinical Factors } \\
\hline Low - Moderate & $-0.26(-4.66,4.15)$ & 0.998 & \multirow{3}{*}{$7.17(0.001)$} \\
\hline Low - Severe & $-9.01(-17.87,-0.15)$ & 0.045 & \\
\hline Severe - Moderate & $-8.75(-16.92,-0.58)$ & 0.035 & \\
\hline
\end{tabular}

ane-way ANOVA test

bPost-hoc comparison using Bonferroni test was applied as assumption for homogeneity of variance was met.

Table 4.1 presents the One- way ANOVA test used to determine the existence of any significant mean difference between the primary and secondary appraisal scores among final year nursing students who had low, moderate and severe levels of stress. The $F$ statistic shows a significant mean difference $(p<0.005)$ between the resilience score and clinical stressor score among three groups of stress levels.

The multivariate analysis shows that clinical placement and resilience is significantly associated with the level of stress. Results of the present study are shown below,

1. Majority of respondents' gender was
female as many as $417(99.3 \%)$
2. The majority of respondents age were
between $22-25$ years old $(69.8 \%)$

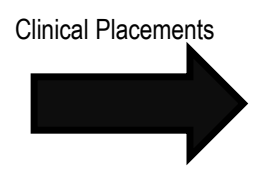

Outcome (stress). The majority experienced stress in moderate category as many as $376(89.5 \%)$

Fig. 3.2: Psychological Stress Experienced by Final Year Nursing Students: Role of the Clinical Environment 


\subsection{Discussion}

The purpose of this study was to identify the sources of stress among final year nursing students by using the PSS scale. The outcome from this study will help researchers, academicians, and nursing students understand the sources of stress and develop management strategies to reduce the stressors. This study has shown that respondents were exposed to a variety of stressors from a clinical perspective, such as fear of making a mistake during clinical placement, having too much clinical responsibility, lack of free time, fear of failing the course, too many procedures to learn in the clinical area, assessment and placement gradings, criticism from peers or staff, and feeling responsible for what happens to patients. Undoubtedly, it is difficult to learn all the procedures during lectures. The level of stress was found to be moderate, while gender and resilience levels were significantly associated with the level of stress. The stressor factor caused by clinical experience shows the highest mean score among those who suffered severe stress. In the One-way ANOVA, the F statistic shows a significant mean difference $(p<0.005)$ in resilience and clinical stressor scores. For resilience, the mean score was highest among those who had low-stress levels. Based on One-way ANOVA, there was a significant mean difference between primary appraisal (stressor) scores and secondary appraisal (mediator) scores among the stress level groups. Hence, it can be concluded that the positive effect (resilience) had significantly contributed to the highest mean score in the low stress group. In contrast, the negative effect (stress due to clinical placement) had a significantly higher mean score in the severe stress group. In conclusion, resilience demonstrated a partial mediation effect in the model as the beta weight was reduced, though not insignificantly.

The findings of this study are also consistent with previous studies, which found a high rate of burn out in nursing students pursuing the Diploma in Nursing course (Seyedfatemi et al., 2007; Watson, 2008; K. Gu, 2015; Ismaile, 2017; Chowdhury, 2017). The inconsistency in the results is because stress among final year nursing students in Malaysia is at a moderate level compared to previous studies, which indicated that the stress level among nursing students is high.

\subsection{Conclusions and Recommendations.}

Initial clinical experience is very stressful for first-year nursing students. Thus, if stressors are identified, and interventions are provided at the earliest possible moment, many physical and psychological consequences of stress can be reduced, and nursing students will be able to lead a productive life. Hence, as nursing tutors, it is necessary to have a better understanding of stress experienced by nursing students and help them cope in a positive manner.

The Lazarus \& Folkman Model is quite long but this study chose this model because it is thorough and consistent with the objectives of this study. Moreover, this model has never been used by Malaysian researchers in the field of nursing. This model states that stress levels are not the same in every individual as it is caused by the interaction between a person and his/her environment. Even in stressful situations, the stress or other circumstances depend on how the individual adapts to the situation.

The present study has highlighted the relevance of the Transactional Model of Stress and Coping (Lazarus \& Folkman, 1984) to guide the study and identify factors that influence stress among final year nursing students in Malaysia. It is suggested that future research examines other pathways in the model, for example, the moderators and mediators of stress among nursing students in Malaysia.

The findings of this study may be beneficial in designing an accurate management package, including the organization of social skills and fast training modules, stress reducing methods, and counselling techniques to overcome stress in final year nursing students studying in ILKKMs. It is also recommended that the faculty and staff be encouraged to work in cooperation with students to improve the students' capabilities. Nursing students in Malaysia, especially final year nursing students, need to be educated about the importance of coping mechanisms that can help them overcome stress.

\section{Acknowledgement}

I would especially like to express my sincere gratitude to my supervisor Dr Zamazaliza Binti Abdul Mulud, nursing students for their kind cooperation in this study, staffs, tutors and friends at ILKKM Sultan Azlan Shah, Universiti Teknologi Mara Malaysia (UiTM) and the Training Management Division, Ministry of Health. Your contributions and assistance are much appreciated.

\section{References}

Abeer Saad Eswi, Sahar Radi \& Hanaa Youssri. (2013). Stress as perceived by baccalaureate Saudi nursing students. Middle-East Journal of Scientific Research 14 (2): 193-202.

Abeer Abd El-Aziz Mohamed Madian, Maha Mahmoud Abdelaziz, and Hend Abo Elsoud Ahmed. (2019). "Level of Stress and Coping Strategies among Nursing Students at Damanhour University, Egypt." American Journal of Nursing Research, vol. 7, no. 5: 684-696. doi: 10.12691/ajnr-7-5-3.

Agacdiken, S., Boga, N. M. \& Ozdelikara, A. (2016). Determination of nursing students' stress level toward nursing education. Journal of Samsun Health Sciences. vol. 1, pp. 1-19.

Alghamdi, S. et al. (2019). Sources of Stress Among Undergraduate Nursing Students. Global Journal of Health Science. Volume. 11 , pp. 9.

Alshagga, Nasir, Behzadnia et al. (2015). Perceived stress and sources of stress among pharmacy students in Malaysian public and private universities: a comparative study. Pharmacy Education. vol.15 (1), pp. $64-68$. 
Al-Zayyat, A. S \& Al-Gamal, E. (2014). Perceived Stress and Coping Strategies among Jordanian Nursing Students during Clinical Practice in Psychiatric/Mental Health Courses. International Journal of Mental Health Nursing, vol. 23, 326-335. Retrieved from http://doi.org/10.1111/inm.12054.

American Holistic Nurses Association. (2015). Retrieved November 3, 2015, from http://www.ahna.org/Resources/Stress-Management/For-Nursing-Students/Exercisesfor Students \# 6 .

Andrew Thomas Reyes. (2015). Nursing students understanding and enactment of resilience: A grounded Theory Study. Retrieved from https://ir.lib.uwo.ca/etd.

Andrew Young Lee. (2014). Improving clinical competence and confidence nursing students through clinical placements. International Journal of nursing. vol. 1, No. 2, pp. 183-209.

Awe, O. O. (2014). Communication Barrier during Clinical Placement: Challenges and Experiences of International Nursing Students. Arcada University of Applied Science.

Chowdhury, et al. (2017). Perceived psychology stress among under graduate medical students: Role of academic factors. Indian Journal of Public Health. Volume 61, pp. 55 .

Diane Chamberlain (2016). Dispositional mindfulness and employment status as predictors of resilience in third year nursing students: A Quantitative Study. Nursing Open. doi : 10.1002/nop2.56.

Hamaideh, S. (2011). Stressors and reactions to stressors among university students. International journal of social psychiatry. vol 57 (1), pp. 69-80.

Ismaile, S. (2017). Stressors' and Coping Strategies among Saudi Nursing Students' in Their Clinical Practice. Health Med Journal. Volume. 10, pp. 25-32.

Ken Gu, Thomas Wong, Min Luo. (2015). Perceived stress among Macao nursing students in the clinical learning environment. International Journal of Nursing Sciences. Volume. 2, pp. 128-133.

Masilamani et at. (2019). Stress, stressors and coping strategies among university nursing students. Malaysian Journal of Public Health Medicine. Volume. 19 (2), pp. 20-28.

Wong et al. (2017). A Study on Nursing Students Stress in Hong Kong. Australian Nursing and Midwifery Conference. Volume 8, pp. 2. Special Issue.

Zakiyah. (2016). Characteristics, stress levels, anxiety, and depression in nursing students working on a thesis. Jurnal Impuls. pp. 140-145.

Zamzaliza Abdul Maulud. (2017). Caregiver burden among caregivers of individuals with severe mental illness: Testing the moderation and mediation models o resilience. Archives of Psychiatric Nursing. Volume 31, pp. 24-30. 